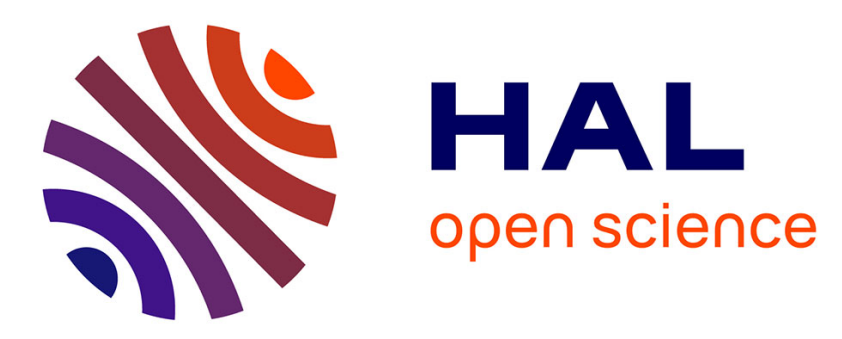

\title{
Absolute Templating of M(111) Cluster Surrogates by Galvanic Exchange
}

Jesse L Peltier, Michele Soleilhavoup, David Martin, Rodolphe Jazzar, Guy Bertrand

\section{- To cite this version:}

Jesse L Peltier, Michele Soleilhavoup, David Martin, Rodolphe Jazzar, Guy Bertrand. Absolute Templating of M(111) Cluster Surrogates by Galvanic Exchange. Journal of the American Chemical Society, 2020. hal-03001149

\section{HAL Id: hal-03001149 \\ https://hal.science/hal-03001149}

Submitted on 12 Nov 2020

HAL is a multi-disciplinary open access archive for the deposit and dissemination of scientific research documents, whether they are published or not. The documents may come from teaching and research institutions in France or abroad, or from public or private research centers.
L'archive ouverte pluridisciplinaire HAL, est destinée au dépôt et à la diffusion de documents scientifiques de niveau recherche, publiés ou non, émanant des établissements d'enseignement et de recherche français ou étrangers, des laboratoires publics ou privés. 


\title{
Absolute Templating of M(111) Cluster Surrogates by Galvanic Exchange
}

Jesse L. Peltier, Michele Soleilhavoup, David Martin, Rodolphe Jazzar and Guy Bertrand

\begin{abstract}
The precise preparation of monodisperse nanomaterials is among the most fundamental tasks in inorganic synthesis and materials science. Achieving this goal by galvanic exchange is hardly predictable and often results in major structural changes and polydisperse mixtures. Taking advantage of the enhanced stability imparted by ambiphilic carbenes, we report and rationalize the absolute templating, the complete exchange of metals in a template, of group 11 clusters across the entire coinage metal family by means of galvanic exchange. We further delineate that these species provide a molecular model for better understanding the reduction of $\mathrm{CO}_{2}$ at $\mathrm{M}(111)$ coinage metal surfaces.
\end{abstract}

\section{Introduction}

The Moche civilization (200 AD, Peru) achieved the plating of gold onto copper artifacts by immersing copper objects in a solution of chloroauric acid,(1) yet they were unaware that this process was governed by the electrochemical differences in these metals. Nowadays, this technique is known as electrochemical replacement by galvanic exchange. It has emerged as a powerful tool to control the metal composition, morphology, and size of nanomaterials (Figure 1a).(2) These features not only determine their physicochemical properties(3) but also their efficiency in innovative applications such as plasmonics,(4) nanomedicine,(5) electronics,(6) and catalysis.(7) Despite these considerable advancements, and the attractiveness of this method, galvanic exchange remains primarily applied in materials science. In this context, extending this technology to ultrasmall nanoparticles (UNPs),(8) a bridge between materials and molecular systems, would allow for transitioning from an observation-driven (top-down) to a design-driven (bottom-up) approach.

The homogeneous preparation and isolation of monodisperse UNPs is broadly described for a number of metals, providing structural modularity, uniformity, and scalability. Moreover, the well-defined structures of UNPs (often confirmed by X-ray crystallography) deliver suitable building blocks and desirable templates for galvanic exchange. However, this strategy suffers from some disadvantages. Aside from rare examples (Figure 1b),(9) it is generally accepted that exchanging more than one atom in a subnanometer sized cluster template is hardly predictable(10) and often leads to polydisperse mixtures through scrambling or aggregation. To complicate the matter further, the mechanism by which these processes transpire remains poorly understood, which inherently impairs future developments.

Close examination of the literature reveals that, although thiolate and phosphine ligands are naturally prone to undergo redistribution, they are predominant in this field.(11) More recently, stable carbenes have increased in popularity because they are able to bind strongly to metal surfaces(12) and impart significant stabilization to UNPs.(13) Using cyclic(alkyl)(amino) carbenes (CAACs),(14) a family of ambiphilic carbenes known to stabilize a number of transition metals atoms in their formal zero oxidation state (e.g., $\mathrm{Fe}, \mathrm{Cu}$, $\mathrm{Au}$, and $\mathrm{Mn}),(15)$ we previously reported the preparation of a trinuclear gold cluster.(16) Taking advantage of the enhanced stability imparted by CAACs, herein, we report the absolute templating (the complete exchange of metals in a template) of group 11 clusters by means of galvanic exchange. This allowed for the synthesis of trinuclear mixed-valent $\mathrm{M}_{2}^{0} \mathrm{M}_{1}$ 
coinage metal clusters for the entire coinage metal family (Figure 1c). To further delineate the use of UNPs as intermediates between homo- and heterogeneous systems, we show that these species provide a molecular model for better understanding the reduction of $\mathrm{CO}_{2}$ at the surface of metals.

a. Nanomaterial Surfaces Hard to predict

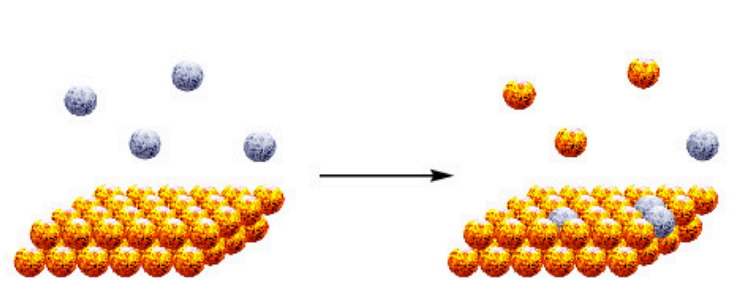

\section{b. Ultra-small nanoparticles Partial templating}

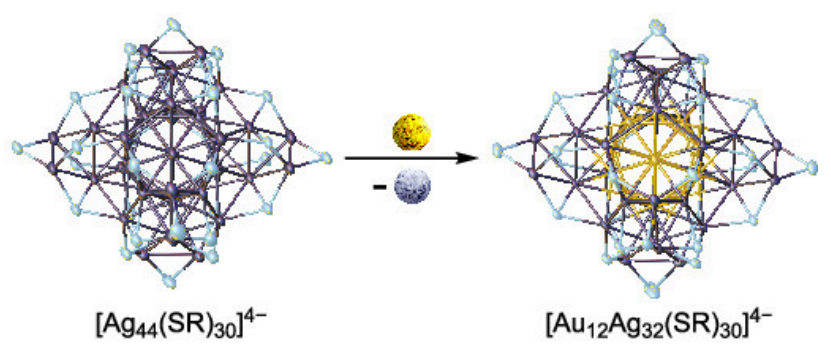

c. CAAC supported clusters Absolute templating (this work)
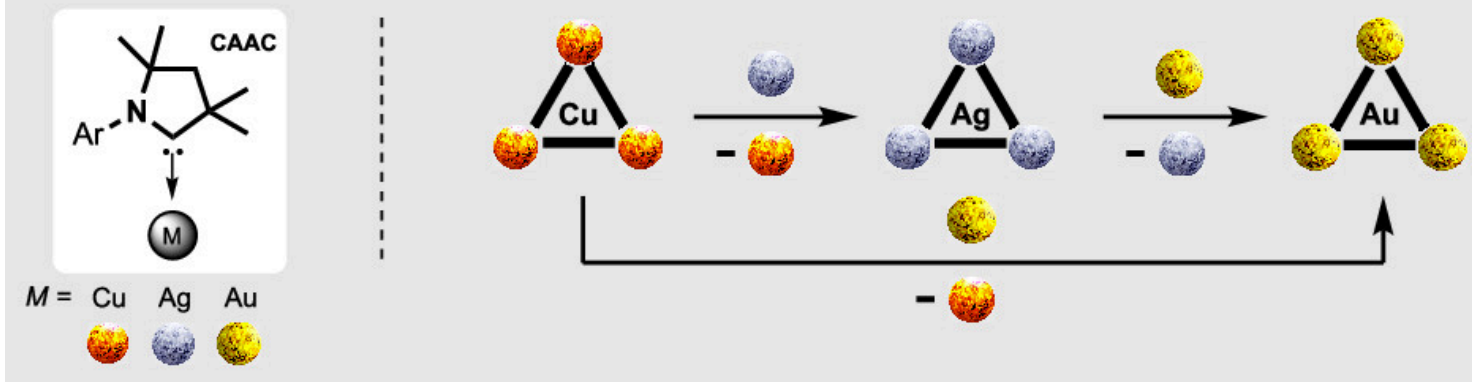

Figure 1. (a) Galvanic exchange on a metal surface involving the replacement of a more active metal (orange atom) for a less reducing one (gray atom) is hard to predict. (b) A rare example of multiple atom galvanic exchange in nanoclusters without loss of structural integrity.(11) (c) The stabilization provided by cyclic(alkyl)(amino)carbenes (CAACs) allows for the absolute templating of trinuclear clusters by galvanic exchange.

\section{Results and Discussion}

The driving force for galvanic exchange relies on the difference in the electrochemical potential between the metal ions. Copper, the least electronegative and consequently the most reducing of the coinage metals, should provide an ideal template. To support this hypothesis, we used DFT to evaluate the thermodynamics of exchanging copper by gold in trinuclear $\mathrm{M}_{2}^{0} \mathrm{M}^{1}$ clusters and found this process to be exergonic by $27.6 \mathrm{kcal} \cdot \mathrm{mol}^{-1}$ (See Method $\mathrm{S} 4$ for details(17)). Encouraged by these results, we set out to prepare the corresponding $\mathrm{Cu}_{2}^{0} \mathrm{Cu}^{1} \mathbf{B}_{1}$ cluster. Despite several attempts, we found that the synthetic strategies previously reported for the gold variant were not amenable to copper. $(13 \mathrm{k}, 16)$ However, reduction of the readily available $\mu^{3}$-oxo- $\left[\mathrm{Cu}\left({ }^{\mathrm{Et}} \mathrm{CAAC}\right)\right]_{3} \mathbf{A}$ with bis(neopentyl-glycolato)diboron afforded the $\mathrm{Cu}_{2}^{0} \mathrm{Cu}^{1}$ trinuclear cluster $\mathbf{B}_{1}$ in excellent yield ( $72 \%$; Figure 2 ). Note that the formation of the diboroxane provides a strong driving force for the reduction of A. X-ray quality crystals obtained from a THF solution layered with diethyl ether confirmed the structure of $\mathbf{B}_{\mathbf{1}}$. Using $\mathbf{B}_{1}$ as a template, we next investigated the galvanic exchange. Upon reaction with $\left({ }^{\mathrm{Et}} \mathrm{CAAC}\right) \mathrm{AuCl}$ as an electrochemical partner, clean formation of the $\mathrm{Au}_{2}^{0} \mathrm{Au}^{1}$ trinuclear cluster $\mathbf{B}_{2}$ and $\left({ }^{\mathrm{Et}} \mathrm{CAAC}\right) \mathrm{CuCl}$ was established by ${ }^{13} \mathrm{C}\left\{{ }^{1} \mathrm{H}\right\}$ NMR spectroscopy. Simple evaporation of the solvent and washing of the residue with diethyl ether quantitatively afforded the trinuclear gold $\mathbf{B}_{\mathbf{2}}$, which was characterized by X-ray crystallography. Inspired by these results, the electrochemical templating of copper by silver was considered. Unexpectedly, reaction of $\mathbf{B}_{\mathbf{1}}$ with three equivalents of $\left({ }^{\mathrm{Et}} \mathrm{CAAC}\right) \mathrm{AgCl}$ led to a rapid plating of silver metal in the reaction vessel. To circumvent this problem, we envisaged exploiting the stronger oxophilicity of copper versus silver as a driving force. $\mathbf{B}_{1}$ cleanly reacted with 
$\left({ }^{\mathrm{Et}} \mathrm{CAAC}\right) \mathrm{AgOPh}$, and a characteristic set of ${ }^{13} \mathrm{C}\left\{{ }^{1} \mathrm{H}\right\}$ NMR signals indicated the formation of $\left({ }^{\mathrm{Et}} \mathrm{CAAC}\right) \mathrm{CuOPh}$. More importantly, two sets of doublets at $258.5\left[{ }^{1} J\left({ }^{107} \mathrm{Ag}-{ }^{13} \mathrm{C}\right)=182.6 \mathrm{~Hz}\right.$ and $\left.{ }^{1} J\left({ }^{109} \mathrm{Ag}_{-}{ }^{13} \mathrm{C}\right)=159.9 \mathrm{~Hz}\right]$ suggested the formation of a new silver compound, which was identified as the trinuclear $\mathbf{B}_{\mathbf{3}}$ by $\mathrm{X}$-ray crystallography. Finally, upon reacting $\mathbf{B}_{\mathbf{3}}$ with $\left({ }^{\mathrm{Et}} \mathrm{CAAC}\right) \mathrm{AuCl}$, we achieved the electrochemical templating from the trinuclear silver to the trinuclear gold $\mathbf{B}_{2}$. While mixed-valent gold clusters have been reported,(18) there are fewer examples of copper and silver analogues.(19,20) More specifically, in the trinuclear series, only the $\mathrm{Au}_{2}^{0} \mathrm{Au}^{1}$ has been isolated $(13 \mathrm{k}, 16)$ whereas the copper and silver analogues were only studied in silico.(21) Structurally, the main difference between the three clusters $\mathbf{B}_{\mathbf{1}}-\mathbf{B}_{\mathbf{3}}$ lies in the $\mathrm{M}-\mathrm{M}$ bond distances which follows the order $\mathrm{Cu}<\mathrm{Au}<\mathrm{Ag}$. This is in good agreement with the larger relativistic effect in gold which results in a reduced covalent radius compared to that of silver.(22)

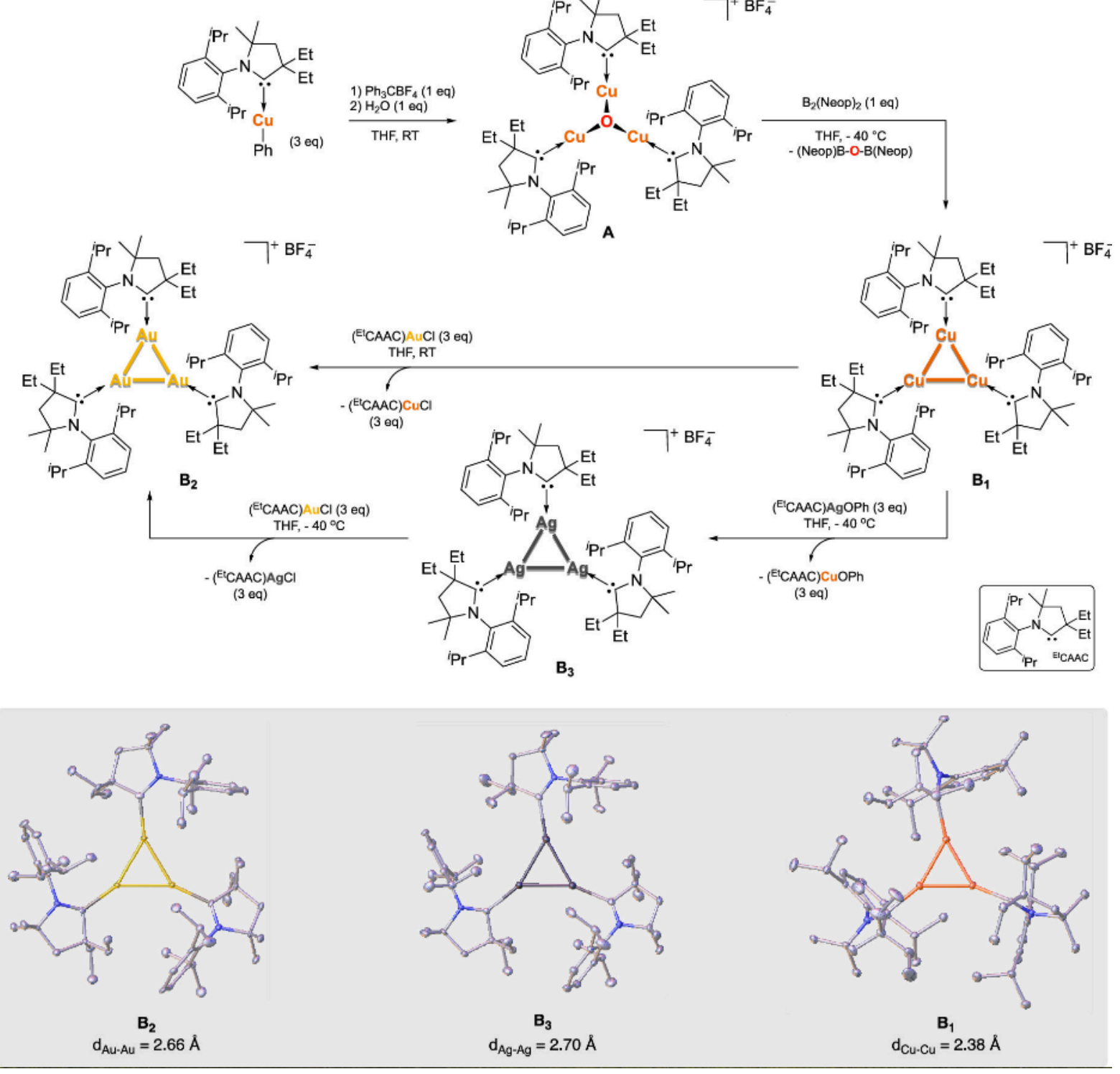

Figure 2. (Top) Trinuclear $\mathrm{Cu}_{2}^{0} \mathrm{Cu}^{1} \mathbf{B}_{1}$ obtained by reduction of the $\mu^{3}$-oxo- $\left[\mathrm{Cu}\left({ }^{\mathrm{Et}} \mathrm{CAAC}\right)\right]_{3} \mathbf{A}$, allows for the absolute templating of trinuclear $\mathrm{M}_{2}^{0} \mathrm{M}^{1}$ by galvanic exchange across the entire coinage metal series without loss of structural integrity. (Bottom) X-ray structures of trinuclear $\mathbf{B}_{\mathbf{1}}-\mathbf{B}_{\mathbf{3}}$; anions and hydrogens have been omitted for clarity.

As with the isolobal triatomic hydrogen ion $\left[\mathrm{H}_{3}\right]^{+},(23) \mathrm{Au}_{2}^{0} \mathrm{Au}^{1}$ clusters are rare examples of $\sigma$-aromatic compounds.(13k) We confirmed that this is also the case with the trinuclear coinage metal series $\mathbf{B}_{\mathbf{1}}-\mathbf{B}_{\mathbf{3}}$, and that CAAC ligands do not significantly perturb the electronic structure in these systems. Indeed, topological analysis of the Electron Localization Function (ELF),(24) revealed the typical trisynaptic basin for a three-center two-electron cycle at the 
orthocenter of the trinuclear metal clusters (Figure 3a). Additionally, strongly negative values for computed nuclear-independent chemical shift (NICS) were found at the vicinity of the center (Figure 3b).(21,25) Cyclic voltammetry studies of $\mathbf{B}_{\mathbf{1}}-\mathbf{B}_{\mathbf{3}}$ indicated irreversible reductions at very low potentials $(<-2 \mathrm{~V})$ and irreversible oxidations above $0.5 \mathrm{~V}$. This suggested that the galvanic replacement is unlikely to occur through an outer sphere reduction pathway, but rather involves an associative addition-elimination type mechanism. Trinuclear cationic $\sigma$-aromatic clusters have been proposed to behave as Lewis bases where the delocalized metal-metal bonds mimic $\pi$-aromatics interactions, and are thus capable of forming tetranuclear 4-center-2 $\mathrm{e}^{-}$clusters with Lewis acidic metal complexes.(26) Taken together, these considerations indicate that, in this case, galvanic templating is likely occurring incrementally via a transient tetranuclear dicationic alloy cluster, wherein the least electronegative metal is replaced, and intermediate trinuclear alloys are formed (Figures $3 \mathrm{c}$ and S4 for the DFT calculated reaction profile).

a.

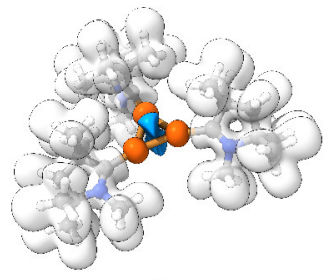

$B_{1}$

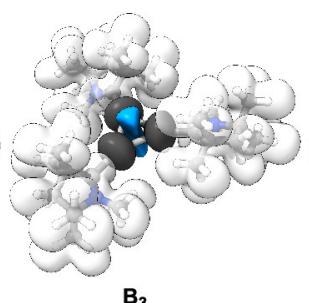

$\mathbf{B}_{3}$

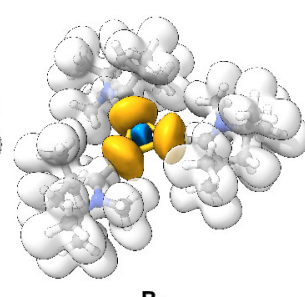

$\mathbf{B}_{2}$

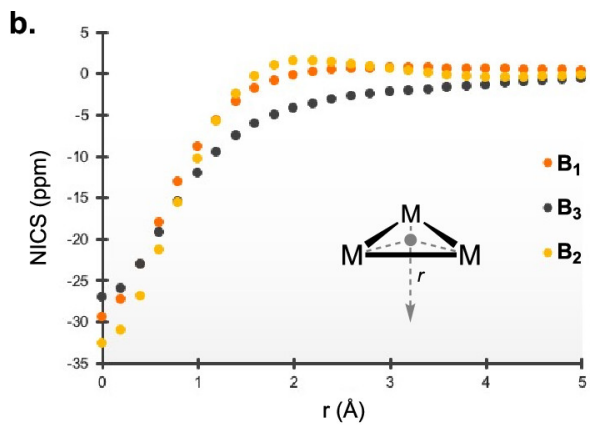

c.

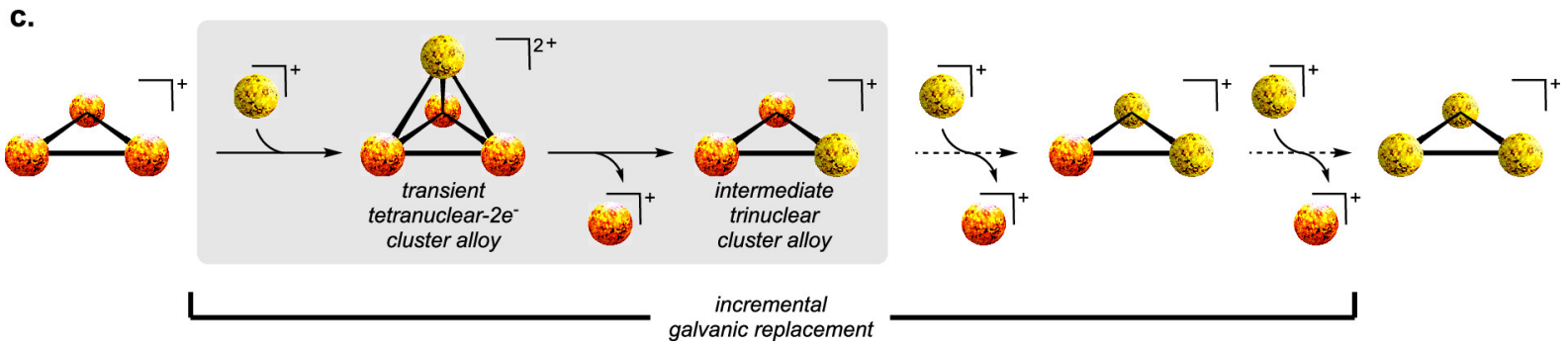

Figure 3. (a) Electron localization function (ELF) in $\mathbf{B}_{1}-\mathbf{B}_{3}$ highlights a trisynaptic basin (blue) of a three-center two-electron cycle. (b) The $\sigma$-aromaticity in trinuclear $\mathbf{B}_{1}-\mathbf{B}_{3}$ is indicated by the NICS scan plots showing large negative values at the ring center, gradually increasing to zero moving away from the ring center.(21) (c) The galvanic templating is proposed to involve sequential and incremental galvanic replacement via transient tetranuclear 4-center-2 $\mathrm{e}^{-}$clusters.

Trinuclear clusters $\mathbf{B}_{\mathbf{1}}-\mathbf{B}_{\mathbf{3}}$ feature a predominately zero oxidation state character and a spatial arrangement reminiscent of a M(111) metal surface. This analogy is further emphasized when considering that the experimental $\mathrm{M}-\mathrm{M}$ bond distances and ELF topology in these clusters, closely mimics those observed in free-standing 2D monolayers (Figure 4a).(27) Consequently, we envisaged that these species might provide a molecular platform for understanding the interaction of small molecules with M(111) metal surfaces.(28) Coinage metal materials in various forms, ranging from polycrystalline foils to nanoparticles, have been thoroughly investigated as heterogeneous electrocatalysts for the reduction of $\mathrm{CO}_{2}$ to commodity chemicals and fuels.(29) Despite these reports, the process by which $\mathrm{CO}_{2}$ is activated at these metal surfaces is still controversial. It has been proposed that charge transfer from the surface to the antibonding orbital of $\mathrm{CO}_{2}$ induces the formation of a bent radical anion $\left(\mathrm{CO}_{2}{ }^{--}\right)$, which can either facilitate (i) $\mathrm{CO}_{2}$ dissociation $\left(\mathrm{CO}_{2} \rightarrow \mathrm{CO}+\mathrm{O}\right)$, (ii) a transient carboxyl $(\mathrm{COOH})$, or (iii) a formate (HCOO) intermediate.(30) Using X-ray photoelectron spectroscopy (APXPS) and high-pressure scanning tunneling microscopy (HPSTM), the gradual coverage of atomically adsorbed oxygen has been observed on $\mathrm{Cu}(111)$ surfaces when subjected to

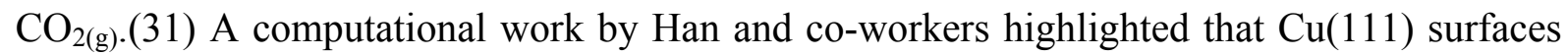


should facilitate $\mathrm{CO}_{2}$ dissociation, whereas $\mathrm{Ag}(111)$ and $\mathrm{Au}(111)$ required a higher $E_{\mathrm{a}}$.(32) To determine if $\mathrm{M}_{2}^{0} \mathrm{M}^{1}(\mathrm{M}=\mathrm{Cu}, \mathrm{Ag}$, and $\mathrm{Au})$ clusters could behave as molecular surrogates for $\mathrm{M}(111)$ surfaces, we investigated the reaction of $\mathrm{CO}_{2}$ (1 atm) with $\mathbf{B}_{\mathbf{1}}-\mathbf{B}_{\mathbf{3}}$ (Figure $4 \mathrm{~b}$ ). In line with the computational data,(32) no reaction was observed upon reacting gold $\mathbf{B}_{\mathbf{2}}$ or silver $\mathbf{B}_{\mathbf{3}}$ clusters with $\mathrm{CO}_{2}$. In marked contrast, using copper $\mathbf{B}_{\mathbf{1}}$, we obtained a clean conversion to the $\mu^{3}$-oxo- $\left[\mathrm{Cu}\left({ }^{\mathrm{Et}} \mathrm{CAAC}\right)\right]_{3} \mathbf{A}$ suggesting the formation of carbon monoxide. We repeated the reaction with ${ }^{13} \mathrm{C}$-labeled carbon dioxide $\left({ }^{13} \mathrm{CO}_{2}\right)$ and were pleased to observe a signal at 181.3 ppm by carbon NMR, characteristic of ${ }^{13} \mathrm{CO}$. Capitalizing on these results and knowing that $\mathbf{A}$ reverts to $\mathbf{B}_{\mathbf{1}}$ in the presence of a reducing agent, the catalytic reduction of $\mathrm{CO}_{2}$ to $\mathrm{CO}$ was performed in the presence of bis(neopentyl-glycolato)diboron; we were pleased to obtain, without optimization, up to $1000 \mathrm{TON}$. Our data support, at the molecular level, current hypotheses regarding the existence of a reductive $\mathrm{CO}_{2}$ dissociation mechanism $\left(\mathrm{CO}_{2} \rightarrow \mathrm{CO}+\right.$ $\mathrm{O})$ by copper surfaces. This process is likely at play in $\mathrm{Cu}$ electrodes which are unique in their ability to convert $\mathrm{CO}_{2}$ to small hydrocarbons (e.g., $\mathrm{CH}_{4}$ and $\left.\mathrm{C}_{2} \mathrm{H}_{4}\right)(33,34)$ but are known to degrade under catalytic conditions.

a.
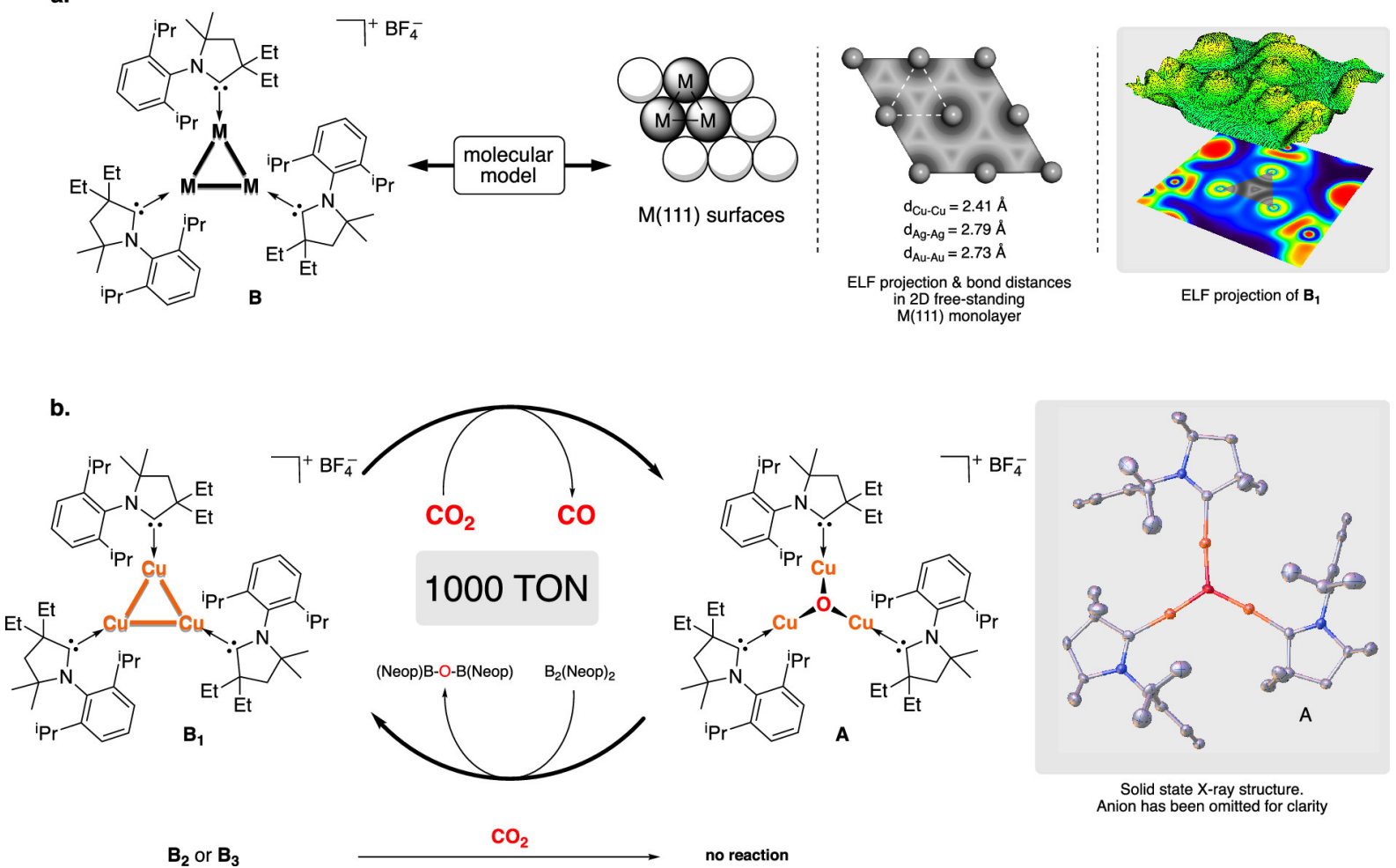

Figure 4. (a) $\mathrm{M}-\mathrm{M}$ bond distances and ELF topology suggest similarities between trinuclear $\mathbf{B}_{\mathbf{1}}-\mathbf{B}_{\mathbf{3}}$ clusters and free-standing $\mathrm{M}(111)$ monolayers. (b) In contrast to the gold and silver equivalent, the trinuclear $\mathrm{Cu}_{2}^{0} \mathrm{Cu}^{1} \mathbf{B}_{1}$ promotes the dissociative reduction of $\mathrm{CO}_{2}$ thereby affording $\mathrm{A}$. Using bis(neopentyl-glycolato)diboron to regenerate $\mathbf{B}_{1}$, up to 1000 TON could be obtained in the reduction of $\mathrm{CO}_{2}$ to $\mathrm{CO}$.

\section{Conclusion}

Although galvanic exchange is commonly employed throughout materials chemistry, it often results in major structural changes including differences in metal nuclearity. In contrast, we have systematically applied galvanic exchange to trinuclear complexes of the coinage metals with maintenance of metal nuclearity throughout the series. These clusters have been synthesized in high yields using standard air-free techniques and thus provide a good platform for further study. Additionally, they feature metals in the predominantly zero oxidation state, making them reminiscent of $\mathrm{M}(111)$ surfaces. To further reinforce the analogy between materials and UNPs, we showed that the copper cluster $\mathbf{B}_{\mathbf{1}}$ promotes $\mathrm{CO}_{2}$ reduction, a process commonly observed for $\mathrm{Cu}(111)$ surfaces. Additionally, the small size of these clusters 
allowed for the isolation and characterization of the $\mu_{3}$-oxo copper complex $\mathbf{A}$, which has the potential to be occurring on $\mathrm{Cu}(111)$ surfaces.(31) Our results highlight the mounting impact of $\pi$-acidic carbene ligands in materials science.(13a)

\section{Experimental Section}

\section{General Considerations}

All manipulations were performed, unless otherwise noted, under an atmosphere of dry argon using standard Schlenk and glovebox techniques. Benzene, tetrahydrofuran, diethyl ether, $n$ pentane, and toluene were freshly distilled over $\mathrm{Na}$ metal under an atmosphere of argon. Hexanes, dichloromethane, and chloroform were freshly distilled over $\mathrm{CaH}_{2}$ under an atmosphere of argon. ${ }^{1} \mathrm{H},{ }^{13} \mathrm{C},{ }^{19} \mathrm{~F}$, and ${ }^{11} \mathrm{~B}$ NMR spectra were recorded on a Varian VX 500 $\mathrm{MHz}$ equipped with a $5 \mathrm{~mm}$ X-Sens cold probe or a Bruker $300 \mathrm{MHz}$ spectrometer. Chemical shifts $(\delta)$ are reported in ppm and are referenced to $\mathrm{SiMe}_{4}\left({ }^{1} \mathrm{H},{ }^{13} \mathrm{C}\right), \mathrm{CFCl}_{3}\left({ }^{19} \mathrm{~F}\right)$, or $\mathrm{BF}_{3} \cdot \mathrm{Et}_{2} \mathrm{O}$ $\left({ }^{11} \mathrm{~B}\right)$. Coupling constants $J$ are given in Hertz as positive values regardless of their real individual signs. NMR multiplicities are abbreviated as follows: $\mathrm{s}=$ singlet, $\mathrm{d}=$ doublet, $\mathrm{t}=$ triplet, $\mathrm{q}=$ quartet, sept $=$ septet, $\mathrm{m}=$ multiplet, $\mathrm{br}=$ broad signal. All spectra were obtained at $298 \mathrm{~K}$ in the solvent indicated, unless otherwise noted. Electrochemical experiments were carried out with a Biologic SP-300 potentiostat. Ferrocene was used as standard, and all reduction potentials are reported with respect to the $E_{1 / 2}$ of the $\mathrm{Fc} / \mathrm{Fc}^{+}$redox couple. The $\mathrm{UV}-$ vis spectra were recorded on a Shimadzu UV-3600 UV/vis/NIR spectrometer. Solvent peaks were digitally subtracted from all solution UV-vis spectra by comparison with an authentic solvent spectrum obtained prior to that of the sample. Melting points were measured with an electrothermal MEL-TEMP apparatus and mass spectra were performed on an Agilent 6230 Accurate-Mass TOFMS spectrometer. Single-crystal X-ray structure determinations were carried out at low temperature on a Bruker P4 Platform, or Kappa diffractometer equipped with a Mo $(\lambda=0.71073 \AA)$ or $\mathrm{Cu}(\lambda=1.54178 \AA)$ radiation source and a Bruker APEX detector. Crystals were selected under oil, mounted on nylon loops, and then immediately placed in a cold stream of $\mathrm{N}_{2}$. All structures were solved by direct methods with SIR 2004 or SHELXS and refined by full-matrix least-squares procedures utilizing SHELXL within the Olex 2 small-molecule solution, refinement, and analysis software package.

\section{Synthesis of Complex $B_{1}$}

$\mu^{3}$-Oxo- $[\mathrm{Cu}(\mathrm{EtCAAC})]_{3} \mathbf{A}(5.0 \mathrm{~g}, 4.05 \mathrm{mmol})$ was dissolved in toluene $(30 \mathrm{~mL})$ and cooled to $-40{ }^{\circ} \mathrm{C}$. Bis(neopentyl glycolato)diboron $(0.915 \mathrm{~g}, 4.05 \mathrm{mmol})$ was added to the solution and kept at $-40{ }^{\circ} \mathrm{C}$ for $12 \mathrm{~h}$. Afterwards, the solution was warmed to room temperature, the dark mother liquor was filtered off, and the crystals were washed with toluene $(3 \times 3 \mathrm{~mL})$. The crystals were then collected, dissolved in THF $(5 \mathrm{~mL})$ at $-40{ }^{\circ} \mathrm{C}$, and layered with toluene to recrystallize again at $-40{ }^{\circ} \mathrm{C}$. The resulting solid was washed with toluene $(3 \times 3 \mathrm{~mL})$ to give a dark yellow crystalline solid (3.55 g, 71.9\% yield). Crystals for X-ray diffraction were grown at room temperature from a THF solution layered with diethyl ether. Characterization data: M.P.: $98-100{ }^{\circ} \mathrm{C}$ (Dec. to brown solid); ${ }^{1} \mathrm{H}$ NMR (THF- $d_{8}, 300 \mathrm{MHz}, 298 \mathrm{~K}$ ): $\delta 7.35$ (t, $J=7.5 \mathrm{~Hz}, 3 \mathrm{H}), 7.21$ (d, $J=7.5 \mathrm{~Hz}, 6 \mathrm{H}), 2.67$ (sept, $J=6.6 \mathrm{~Hz}, 6 \mathrm{H}), 2.02-1.95$ (m, 6H), 1.90 $(\mathrm{s}, 6 \mathrm{H}), 1.66-1.58(\mathrm{~m}, 6 \mathrm{H}), 1.23-1.20(\mathrm{~m}, 36 \mathrm{H}), 1.09(\mathrm{t}, J=7.4 \mathrm{~Hz}, 18 \mathrm{H}), 0.77(\mathrm{~d}, J=6.6 \mathrm{~Hz}$, $18 \mathrm{H}) \mathrm{ppm} ;{ }^{13} \mathrm{C}\left\{{ }^{1} \mathrm{H}\right\}$ NMR (THF- $\left.d_{8}, 125.7 \mathrm{MHz}, 298 \mathrm{~K}\right): \delta 252.7$ (CCarbene), 146.1 (Cq), $135.4(\mathrm{Cq}), 130.1$ (CHAr), 125.1 (CHAr), $81.8(\mathrm{Cq}), 64.4(\mathrm{Cq}), 43.0\left(\mathrm{CH}_{2}\right), 31.9\left(\mathrm{CH}_{2}\right), 29.9$ (CH), $29.2\left(\mathrm{CH}_{3}\right), 28.6\left(\mathrm{CH}_{3}\right), 22.0\left(\mathrm{CH}_{3}\right), 9.9\left(\mathrm{CH}_{3}\right) \mathrm{ppm} ;{ }^{19} \mathrm{~F}$ NMR (THF-d $d_{8}, 282 \mathrm{MHz}, 298$ $\mathrm{K}): \delta-154.5$ (10B), -154.6 (11B) ppm; ${ }^{11} \mathrm{~B}\left\{{ }^{1} \mathrm{H}\right\}$ NMR (THF- $\left.d_{8}, 160 \mathrm{MHz}, 298 \mathrm{~K}\right): \delta-1.1$ ppm. 


\section{Acknowledgments}

This work was supported by the U.S. Department of Energy, Office of Science, Basic Energy Sciences, Catalysis Science Program, under Award No. DE-SC0009376. J.L.P. thanks both the National Science Foundation Graduate Research Fellowship Program under Grant No. DGE-1650112 and the Tribal Membership Initiative fellowship administered by the UC San Diego Graduate Division for financial support. We also thank Dr. Milan Gembicky for his crystallographic expertise and the Keck Foundation for providing computational resources.

\section{References}

1. Lechtman, H. A pre-columbian technique for electrochemical replacement plating of gold and silver on copper objects. JOM 1979, 31, 154- 160.

2. (a) Wang, X.; Feng, J.; Bai, Y.; Zhang, Q.; Yin, Y. Synthesis, Properties, and Applications of Hollow Micro-/Nanostructures. Chem. Rev. 2016, 116, 10983-11060. (b) Gilroy, K. D.; Ruditskiy, A.; Peng, H.-C.; Qin, D.; Xia, Y. Bimetallic nanocrystals: syntheses, properties, and applications. Chem. Rev. 2016, 116, 10414- 10472.

3. Kang, X.; Zhu, M. Tailoring the photoluminescence of atomically precise nanoclusters. Chem. Soc. Rev. 2019, 48, 2422- 2457.

4. Baffou, G.; Quidant, R. Nanoplasmonics for chemistry. Chem. Soc. Rev. 2014, 43, 38983907.

5. Pang, B.; Yang, X.; Xia, Y. Putting gold nanocages to work for optical imaging, controlled release and cancer theranostics. Nanomedicine 2016, 11, 1715- 1728.

6. Kamyshny, A.; Magdassi, S. Conductive nanomaterials for printed electronics. Small 2014, 10, 3515- 3535 .

7. Da Silva, A. G. M.; Rodrigues, T. S.; Haigh, S. J.; Camargo, P. H. C. Galvanic replacement reaction: recent developments for engineering metal nanostructures towards catalytic applications. Chem. Commun. 2017, 53, 7135- 7148.

8. (a) Du, Y.; Sheng, H.; Astruc, D.; Zhu, M. Atomically precise noble metal nanoclusters as efficient catalysts: a bridge between structure and properties. Chem. Rev. 2020, 120, 526622. (b) Astruc, D. Introduction: Nanoparticles in Catalysis. Chem. Rev. 2020, 120 (2), 461- 463. (c) Higaki, T.; Li, Q.; Zhou, M.; Zhao, S.; Li, Y.; Li, S.; Jin, R. Toward the tailoring chemistry of metal nanoclusters for enhancing functionalities. Acc. Chem. Res. 2018, 51, 2764- 2773.

9. Yao, Q.; Feng, Y.; Fung, V.; Yu, Y.; Jiang, D.-e.; Yang, J.; Xie, J. Precise control of alloying sites of bimetallic nanoclusters via surface motif exchange reaction. Nat. Commun. 2017, 8, 1555 .

10. (a) Wang, S.; Li, Q.; Kang, X.; Zhu, M. Customizing the structure, composition, and properties of alloy nanoclusters by metal exchange. Acc. Chem. Res. 2018, 51, 2784- 2792. (b) Hossain, S.; Niihori, Y.; Nair, L. V.; Kumar, B.; Kurashige, W.; Negishi, Y. Alloy clusters: precise synthesis and mixing effects. Acc. Chem. Res. 2018, 51, 3114- 3124

11. (a) Yao, Q.; Chen, T.; Yuan, X.; Xie, J. Toward total synthesis of thiolate-protected metal nanoclusters. Acc. Chem. Res. 2018, 51, 1338- 1348. (b) Konishi, K.; Iwasaki, M.; Shichibu, Y. Phosphine-ligated gold clusters with core+exo geometries: unique properties and interactions at the ligand-cluster interface. Acc. Chem. Res. 2018, 51, 3125-3133. (c) Kang, X.; Zhu, M. Transformation of atomically precise nanoclusters by ligand-exchange. 
Chem. Mater. 2019, 31, 9939- 9969. (d) Häkkinen, H. The Gold-Sulfur Interface at the Nanoscale. Nat. Chem. 2012, 4, 443- 455.

12. (a) Bakker, A.; Freitag, M.; Kolodzeiski, E.; Bellotti, P.; Timmer, A.; Ren, J.; Schulze Lammers, B.; Moock, D.; Roesky, H. W.; Monig, H.; Amirjalayer, S.; Fuchs, H.; Glorius, F. An electron-rich cyclic (alkyl)(amino) carbene on $\mathrm{Au}(111), \operatorname{Ag}(111)$ and $\mathrm{Cu}(111)$ surfaces. Angew. Chem., Int. Ed. 2020, 59, 13643- 13646. (b) MacLeod, M. J.; Goodman, A. J.; Ye, H.; Nguyen, H. V.-T.; Van Voorhis, T.; Johnson, J. A. Robust gold nanorods stabilized by bidentate n-heterocyclic-carbene-thiolate ligands. Nat. Chem. 2019, 11, 5763. (c) Lv, A.; Freitag, M.; Chepiga, K. M.; Schäfer, A. H.; Glorius, F.; Chi, L. Nheterocyclic-carbene-treated gold surfaces in pentacene organic field-effect transistors: improved stability and contact at the interface. Angew. Chem., Int. Ed. 2018, 57, 47924796. (d) Doud, E. A.; Inkpen, M. S.; Lovat, G.; Montes, E.; Paley, D. W.; Steigerwald, M. L.; Vázquez, H.; Venkataraman, L.; Roy, X. In situ formation of N-heterocyclic carbenebound single-molecule junctions. J. Am. Chem. Soc. 2018, 140, 8944- 8949. (e) Ye, R.; Zhukhovitskiy, A. V.; Kazantsev, R. V.; Fakra, S. C.; Wickemeyer, B. B.; Toste, F. D.; Somorjai, G. A. Supported au nanoparticles with n-heterocyclic carbene ligands as active and stable heterogeneous catalysts for lactonization. J. Am. Chem. Soc. 2018, 140, 4144 4149. (f) Crudden, C. M.; Horton, J. H.; Narouz, M. R.; Li, Z.; Smith, C. A.; Munro, K.; Baddeley, C. J.; Larrea, C. R.; Drevniok, B.; Thanabalasingam, B.; McLean, A. B.; Zenkina, O. V.; Ebralidze, I. I.; She, Z.; Kraatz, H.-B.; Mosey, N. J.; Saunders, L. N.; Yagi, A. Simple direct formation of self-assembled N-heterocyclic carbene monolayers on gold and their application in biosensing. Nat. Commun. 2016, 7, 12654. (g) Wang, G.; Rühling, A.; Amirjalayer, S.; Knor, M.; Ernst, J. B.; Richter, C.; Gao, H.-J.; Timmer, A.; Gao, H.Y.; Doltsinis, N. L.; Glorius, F.; Fuchs, H. Ballbot-type motion of N-heterocyclic carbenes on gold surfaces. Nat. Chem. 2017, 9, 152- 156. (h) Crudden, C. M.; Horton, J. H.; Ebralidze, I. I.; Zenkina, O. V.; McLean, A. B.; Drevniok, B.; She, Z.; Kraatz, H.-B.; Mosey, N. J.; Seki, T.; Keske, E. C.; Leake, J. D.; Rousina-Webb, A.; Wu, G. Ultra stable self-assembled monolayers of N-heterocyclic carbenes on gold. Nat. Chem. 2014, 6, 409414. (i) Zhukhovitskiy, A. V.; Mavros, M. G.; Van Voorhis, T.; Johnson, J. A. J. Am. Chem. Soc. 2013, 135, 7418- 7421.

13. (a) Smith, C. A.; Narouz, M. R.; Lummis, P. A.; Singh, I.; Nazemi, A.; Li, C.-H.; Crudden, C. M. N-heterocyclic carbenes in materials chemistry. Chem. Rev. 2019, 119, 4986-5056. (b) Narouz, M.; Osten, R. K. M.; Unsworth, P. J.; Man, R. W. Y.; Salor- inne, K.; Takano, S.; Tomihara, R.; Kaappa, S.; Malola, S.; Dinh, C.-T.; Padmos, J. D.; Ayoo, K.; Garrett, P. J.; Nambo, M.; Horton, J. H.; Sargent, E. H.; Häkkinen, H.; Tsukuda, T.; Crudden, C. M. $\mathrm{N}$-heterocyclic carbene-functionalized magic-number gold nanoclusters. Nat. Chem. 2019, 11, 419- -425. (c) Man, R. W. Y.; Li, C.-H.; MacLean, M. W. A.; Zenkina, O. V.; Zamora, M. T.; Saunders, L. N.; Rousina-Webb, A.; Nambo, M.; Crudden, C. M. Ultrastable gold nanoparticles modified by bidentate n-heterocyclic carbene ligands. J. Am. Chem. Soc. 2018, 140, 1576- 1579. (d) Ernst, J. B.; Schwermann, C.; Yokota, G.-I.; Tada, M.; Muratsugu, S.; Doltsinis, N. L.; Glorius, F. Molecular adsorbates switch on heterogeneous catalysis: induction of reactivity by n-heterocyclic carbenes. J. Am. Chem. Soc. 2017, 139, 9144- 9147. (e) Wu, C.-Y.; Wolf, W. J.; Levartovsky, Y.; Bechtel, H. A.; Martin, M. C.; Toste, F. D.; Gross, E. High-spatial-resolution mapping of catalytic reactions on single particles. Nature 2017, 541, 511- 515. (f) Ernst, J. B.; Muratsugu, S.; Wang, F.; Tada, M.; Glorius, F. Tunable heterogeneous catalysis: n-heterocyclic carbenes as ligands for supported heterogeneous $\mathrm{ru} / \mathrm{k}-\mathrm{al}_{2} \mathrm{O}_{3}$ catalysts to tune reactivity and selectivity. J. Am. Chem. Soc. 2016, 138, 10718- 10721. (g) MacLeod, M. J.; Johnson, J. A. PEGylated Nheterocyclic carbene anchors designed to stabilize gold nanoparticles in biologically relevant media. J. Am. Chem. Soc. 2015, 137, 7974- 7977. (h) Khalili Najafabadi, B.; 
Corrigan, J. F. N-Heterocyclic carbene stabilized Ag-P nanoclusters. Chem. Commun. 2015, 51, 665- 667. (i) Zhukhovitskiy, A. V.; MacLeod, M. J.; Johnson, J. A. Carbene ligands in surface chemistry: from stabilization of discrete elemental allotropes to modification of nanoscale and bulk substrates. Chem. Rev. 2015, 115, 11503-11532. (j) Baquero, E. A.; Tricard, S.; Flores, J. C.; de Jesus, E.; Chaudret, B. Highly stable watersoluble platinum nanoparticles stabilized by hydrophilic N-heterocyclic carbenes. Angew. Chem., Int. Ed. 2014, 53, 13220- 13224. (k) Robilotto, T. J.; Bacsa, J.; Gray, T. G.; Sadighi, J. P. Synthesis of a trigold monocation: an isolobal analogue of $\left[\mathrm{H}_{3}\right]^{+}$. Angew. Chem., Int. Ed. 2012, 51, 12077- 12080.

14. (a) Melaimi, M.; Jazzar, R.; Soleilhavoup, M.; Bertrand, G. Cyclic (alkyl)(amino)carbenes (caacs): recent developments. Angew. Chem., Int. Ed. 2017, 56, 10046- 10068. (b) Paul, U. S. D.; Radius, U. What wanzlick did not dare to dream: cyclic (alkyl)(amino)carbenes (caacs) as new key players in transition-metal chemistry. Eur. J. Inorg. Chem. 2017, 2017, 3362- 3375. (c) Soleilhavoup, M.; Bertrand, G. Cyclic (alkyl)(amino)carbenes (CAACs): stable carbenes on the rise. Acc. Chem. Res. 2015, 48, 256- 266. (d) Lavallo, V.; Canac, Y.; Prasang, C.; Donnadieu, B.; Bertrand, G. Stable cyclic (alkyl)(amino)carbenes as rigid or flexible, bulky, electron-rich ligands for transition-metal catalysts: a quaternary carbon atom makes the difference. Angew. Chem., Int. Ed. 2005, 44, 5705- 5709.

15. (a) Jazzar, R.; Soleilhavoup, M.; Bertrand, G. Cyclic (alkyl)- and (aryl)-(amino)carbene coinage metal complexes and their applications. Chem. Rev. 2020, 120, 4141-4168. (b) Roy, S.; Mondal, K. C.; Roesky, H. W. Cyclic alkyl(amino) carbene stabilized complexes with low coordinate metals of enduring nature. Acc. Chem. Res. 2016, 49, 357-369.

16. Jin, L.; Weinberger, D. S.; Melaimi, M.; Moore, C. E.; Rheingold, A. L.; Bertrand, G. Trinuclear gold clusters supported by cyclic (alkyl)(amino)carbene ligands: mimics for gold heterogeneous catalysts. Angew. Chem., Int. Ed. 2014, 53, 9059- 9063.

17. All computational results are available for download free of charge from UCSD Library Digital Collections: Peltier, J. L.; Soleilhavoup, M.; Martin, D.; Jazzar, R.; Bertrand, G. Absolute Templating of M(111) Cluster Surrogates by Galvanic Exchange.

18. Jin, R.; Zeng, C.; Zhou, M.; Chen, Y. Atomically precise colloidal metal nanoclusters and nanoparticles: fundamentals and opportunities. Chem. Rev. 2016, 116, 10346- 10413.

19. (a) Han, B.-L.; Liu, Z.; Feng, L.; Wang, Z.; Gupta, R. K.; Aikens, C. M.; Tung, C.-H.; Sun, D. Polymorphism in atomically precise $\mathrm{Cu}_{23}$ nanocluster incorporating tetrahedral $\left[\mathrm{Cu}_{4}\right]^{0}$ kernel. J. Am. Chem. Soc. 2020, 142, 5834 - 5841. (b) Ghosh, A.; Huang, R.-W.; Alamer, B.; Abou-Hamad, E.; Hedhili, M. N.; Mohammed, O. F.; Bakr, O. M. $\left[\mathrm{Cu}_{61}(\mathrm{StBu})_{26} \mathrm{~S}_{6} \mathrm{Cl}_{6} \mathrm{H}_{14}\right]^{+}$: A Core-Shell Superatom Nanocluster with a Quasi-J36 Cu19 Core and an "18-Crown-6" Metal-Sulfide-like Stabilizing Belt. ACS Materials Lett. 2019, 1, 297- 302. (c) Chakrahari, K. K.; Liao, J. H.; Kahlal, S.; Liu, Y. C.; Chiang, M. H.; Saillard, J. Y.; Liu, C. W. [ $\mathrm{Cu}_{13}\left\{\mathrm{~S}_{2} \mathrm{CN}(\mathrm{n}) \mathrm{Bu}_{2}\right\}_{6}$ (acety- lide) $]_{4}^{+}$: A Two-Electron Superatom. Angew. Chem., Int. Ed. 2016, 55, 14704- 14708. (d) Nguyen, T.-A. D.; Jones, Z. R.; Goldsmith, B. R.; Buratto, W. R.; Wu, G.; Scott, S. L.; Hayton, T. W. A $\mathrm{Cu}_{25}$ nanocluster with partial $\mathrm{Cu}(0)$ character. J. Am. Chem. Soc. 2015, 137, 13319- 13324.

20. (a) Wang, Z.-Y.; Wang, M.-Q.; Li, Y.-L.; Luo, P.; Jia, T.-T.; Huang, R.-W.; Zang, S.-Q.; Mak, T. C. W. Atomically Precise Site-Specific Tailoring and Directional Assembly of Superatomic Silver Nanoclusters. J. Am. Chem. Soc. 2018, 140, 1069- 1076. (b) Joshi, C. P.; Bootharaju, M. S.; Alhilaly, M. J.; Bakr, O. M. First Silver Analogue to gold (or so they claim) also with $\operatorname{Ag}(0)$ character: $\left[\mathrm{Ag}_{25}(\mathrm{SR})_{18}\right]^{-}$: The "Golden" Silver Nanoparticle. J. Am. Chem. Soc. 2015, 137, 11578- 11581. (c) Dhayal, R. S.; Liao, J. H.; Liu, Y. C.; Chiang, M.-H.; Kahlal, S.; Saillard, J. Y.; Liu, C. W. $\left[\mathrm{Ag}_{21}\left\{\mathrm{~S}_{2} \mathrm{P}(\mathrm{O} i \mathrm{Pr})_{2}\right\}_{1}\right]^{+}$: An Eight-Electron Superatom. Angew. Chem., Int. Ed. 2015, 54, 3702- 3706. (d) Desireddy, A.; Conn, B. E.; Guo, J.; Yoon, B.; Barnett, R. N.; Monahan, B. M.; Kirschbaum, K.; Griffith, W. P.; 
Whetten, R. L.; Landman, U.; Bigioni, T. P. Ultrastable silver nanoparticles. Nature 2013, 501, 399- 402.

21. Pan, S.; Saha, R.; Mandal, S.; Chattaraj, P. K. $\sigma$-Aromatic cyclic $\mathrm{M}_{3}^{+}(\mathrm{M}=\mathrm{Cu}, \mathrm{Ag}, \mathrm{Au})$ clusters and their complexation with dimethyl imidazol-2-ylidene, pyridine, isoxazole, furan, noble gases and carbon monoxide. Phys. Chem. Chem. Phys. 2016, 18, 1166111676.

22. Schwarz, H. Relativistic effects in gas-phase ion chemistry: an experimentalist's view. Angew. Chem., Int. Ed. 2003, 42, 4442- 4454.

23. Havenith, R. W.A.; De Proft, F.; Fowler, P. W.; Geerlings, P. Geerlings, P. $\sigma$-Aromaticity in $\mathrm{H}_{3}{ }^{+}$and $\mathrm{Li}_{3}{ }^{+}$: Insights from ring-current maps. Chem. Phys. Lett. 2005, 407, 391- 396.

24. Silvi, B.; Savin, A. Classification of chemical bonds based on topological analysis of electron localization functions. Nature 1994, 371, 683- 686.

25. Stanger, A. Nucleus-independent chemical shifts (NICS): distance dependence and revised criteria for aromaticity and antiaromaticity. J. Org. Chem. 2006, 71, 883- 893.

26. Wang, Y.; Monfredini, A.; Deyris, P.-Al.; Blanchard, F.; Derat, E.; Maestri, G.; Malacria, M. All-metal aromatic cationic palladium triangles can mimic aromatic donor ligands with lewis acidic cations. Chem. Sci. 2017, 8, 7394- 7402.

27. Yang, L.-M.; Frauenheim, T.; Ganz, E. Properties of the free-standing two-dimensional copper monolayer. J. Nanomater. 2016, 2016, 1.

28. Chakraborty, I.; Pradeep, T. Atomically precise clusters of noble metals: emerging link between atoms and nanoparticles. Chem. Rev. 2017, 117, 8208-8271.

29. (a) Xie, C.; Niu, Z.; Kim, D.; Li, M.; Yang, P. Surface and interface control in nanoparticle catalysis. Chem. Rev. 2020, 120, 1184- 1249. (b) Zhu, W.; Michalsky, R.; Metin, Ö.; Lv, H.; Guo, S.; Wright, C. J.; Sun, X.; Peterson, A. A.; Sun, S. Monodisperse au nanoparticles for selective electrocatalytic reduction of $\mathrm{CO}_{2}$ to CO. J. Am. Chem. Soc. 2013, 135, 16833- 16836. (c) Kauffman, D. R.; Alfonso, D.; Matranga, C.; Qian, H.; Jin, $\mathrm{R}$. Experimental and computational investigation of $\mathrm{Au}_{25}$ clusters and $\mathrm{CO}_{2}$ : a unique interaction and enhanced electrocatalytic activity. J. Am. Chem. Soc. 2012, 134, 1023710243. (d) Hori, Y.; Murata, A.; Takahashi, R.; Suzuki, S. Electrochemical reduction of carbon monoxide to hydrocarbons at various metal electrodes in aqueous solution. Chem. Lett. 1987, 16, 1665- 1668.

30. (a) Wang, S.-G.; Liao, X.-Y.; Cao, D.-B.; Huo, C.-F.; Li, Y.-W.; Wang, J.; Jiao, H. Factors controlling the interaction of $\mathrm{CO}_{2}$ with transition metal surfaces. J. Phys. Chem. C 2007, 111, 16934 - 16940. (b) Feaster, J. T.; Shi, C.; Cave, E. R.; Hatsukade, T.; Abram, D. N.; Kuhl, K. P.; Hahn, C.; Nørskov, J. K.; Jaramillo, T. F. Understanding selectivity for the electrochemical reduction of carbon dioxide to formic acid and carbon monoxide on metal electrodes. ACS Catal. 2017, 7, 4822- 4827.

31. Eren, B.; Weatherup, R. S.; Liakakos, N.; Somorjai, G. A.; Salmeron, M. Dissociative carbon dioxide adsorption and morphological changes on $\mathrm{Cu}(100)$ and $\mathrm{Cu}(111)$ at ambient pressures. J. Am. Chem. Soc. 2016, 138, 8207-8211.

32 Ko, J.; Kim, B.-K.; Han, J. W. Density functional theory study for catalytic activation and dissociation of $\mathrm{CO}_{2}$ on bimetallic alloy surfaces. J. Phys. Chem. C 2016, 120, 3438- 3447.

33. Nie, X.; Esopi, M. R.; Janik, M. J.; Asthagiri, A. Selectivity of $\mathrm{CO}_{2}$ reduction on copper electrodes: the role of the kinetics of elementary steps. Angew. Chem., Int. Ed. 2013, 52, 2459- 2462.

34. Kuhl, K. P.; Cave, E. R.; Abram, D. N.; Jaramillo, T. F. New insights into the electrochemical reduction of carbon dioxide on metallic copper surfaces. Energy Environ. Sci. 2012, 5, 7050- 7059 . 